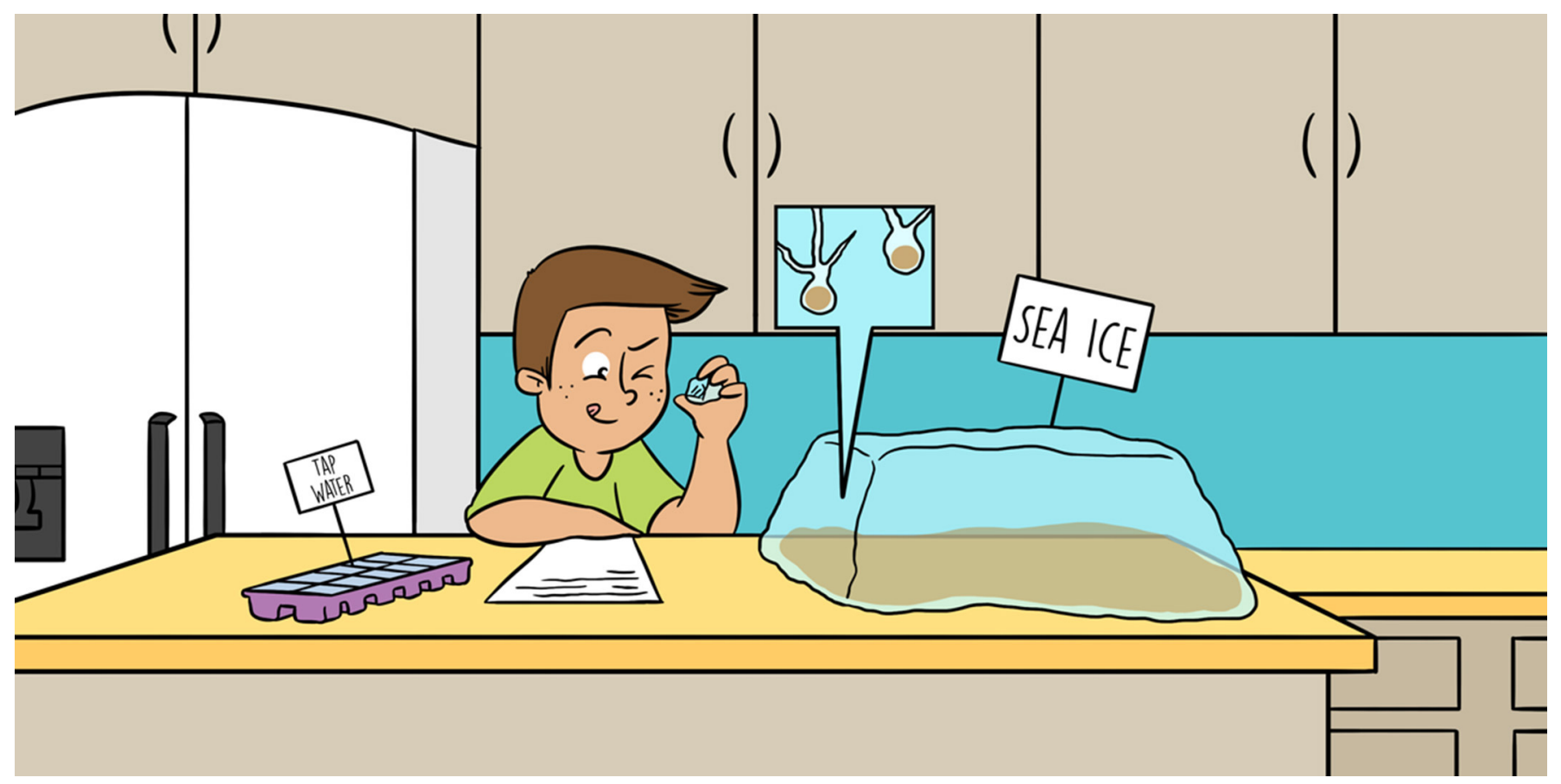

\title{
FREEZING IN THE SUN
}

Giulia Castellani ${ }^{1 *}$, Gaëlle Veyssiere ${ }^{2}$, Frank Kauker ${ }^{3,4}$, Michael Karcher ${ }^{3,4}$, Julienne Stroeve ${ }^{5,6}$, Jeremy P. Wilkinson ${ }^{2}$, Hauke Flores ${ }^{1}$ and Marcel Nicolaus ${ }^{1}$

${ }^{1}$ Department of Biosciences - Polar Biological Oceanography Group, Alfred Wegener Institute Helmholtz Centre for Polar and Marine Research, Bremerhaven, Germany

${ }^{2}$ British Antarctic Survey, Cambridge, United Kingdom

${ }^{3}$ Department of Climate Sciences - Sea Ice Physics, Alfred Wegener Institute Helmholtz Centre for Polar and Marine Research, Bremerhaven, Germany

${ }^{4}$ Ocean Atmosphere Systems GmbH, Hamburg, Germany

${ }^{5}$ Polar Research Group, University College London, London, United Kingdom

${ }^{6}$ Department of Environment and Geography, University of Manitoba, Winnipeg, MB, Canada

YOUNG REVIEWERS:

ECOLE PRIMAIRE

PAUL BAUDRIN AGE: 10
When the air is very cold, water at the surface of the ocean freezes, forming sea ice. Parts of the Arctic Ocean are covered by sea ice during the entire year. Often, snow falls onto the sea ice. Despite the cold, many plants and animals can live in the Arctic Ocean, some in the water, and some even in the sea ice. Particularly, algae can live in small bubbles in the sea ice. Like other plants, algae need energy to grow. This energy comes from food and sunlight. But how can the sunlight reach these little algae living inside the sea ice? From the sun, the light must pass through the atmosphere, the snow, and finally the sea ice itself. In this article, we describe how ice algae can live in this special environment and we explain what influences how much light reaches the algae to make them grow. 
Figure 1

The left panel shows a picture of a sea ice block, turned horizontally. A brownish layer of algae is visible at the bottom. The middle panel shows the small bubbles, connected by veins, that make up the brine pockets that the algae live in. The right panel shows one pocket full of algae, which create a greenish-brown color.

\section{SEA ICE}

Frozen ocean water.

\section{BRINE POCKETS}

Small bubbles of salty water inside the sea ice.

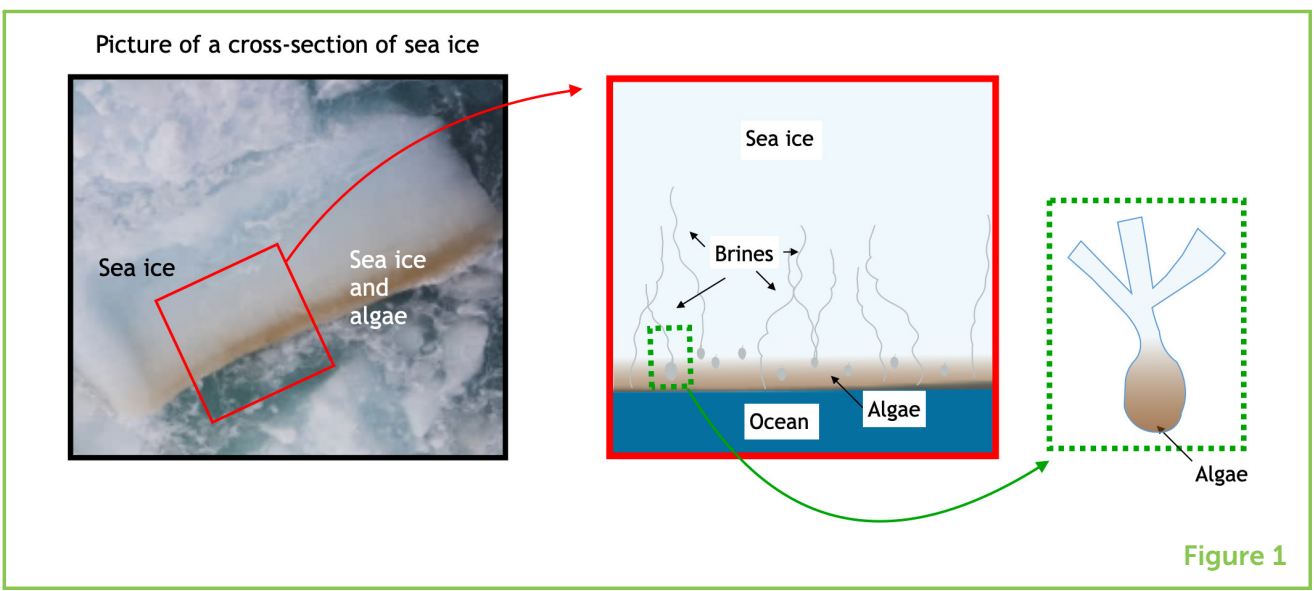

\section{SEA ICE: THE HOUSE OF ALGAE}

If you think about an ice cube, like the ones in a cold drink in summer, you can hardly believe that something could live inside it. But the sea ice, which is ice formed from freezing sea water, can indeed be the home for little organisms. How is this possible, and where do these organisms live? Ocean water contains both salt and algae. When the water freezes, some of these salt grains, and some algae, remain trapped in the ice. The salt grains melt some of the ice around them and create little bubbles filled with salty water [1]. These bubbles are called brine pockets. The brine pockets can be up to $5 \mathrm{~mm}$ in size, the diameter of a pencil, and they grow larger during the spring and summer seasons. Since algae are smaller than $1 \mathrm{~mm}$, they can comfortably live inside the brine pockets (Figure 1). As the sea ice grows thicker, the brine pockets are pushed toward the bottom of the sea ice. Thus, algae live mainly in the bottom layer of the sea ice (Figure 1).

\section{HOW BIG IS ALGAE'S HOUSE?}

An ice cube in your drink is relatively small; you can easily take it in your hand. But how big is sea ice? Sea ice covers large parts of the Arctic Ocean. It starts to form in autumn, when the air gets increasingly colder, and it reaches its maximum extent in late winter (February to March). The sea ice starts to decrease its extent again in late spring when the sun warms up the atmosphere and the surface of the ice, causing the ice to melt. We can imagine sea ice as a large blanket covering the Arctic Ocean. This blanket gets larger when it is cold and shrinks again when it is warmer. The sea ice also becomes thicker in winter and thinner again in summer. Sometimes the ice wrinkles and it can also break into pieces of varying sizes, from small pieces with a diameter of just a few meters up to large pieces of several kilometers. In winter the ice is the thickest, the blanket is the largest, and the most wrinkles are present. 


\section{PHOTOSYNTHESIS}

A process by which plants use sunlight to produce food and energy

\section{MOLECULES}

Very small particles that are the material from which every solid, liquid, or gaseous material is made.
The extent of sea ice in winter can reach 14 million $\mathrm{km}^{2}$, an area of about 2 billion football fields, and it can easily be $2 \mathrm{~m}$ thick, same as the height of a basketball player. When it crumples, the ice can create wrinkles that are 3 or $4 \mathrm{~m}$ high above the water and that reach down $10-15 \mathrm{~m}$ into the water. Moreover, in winter, snow accumulates on top of the sea ice. The snow is usually $20-30 \mathrm{~cm}$ thick. If you imagine the Arctic sea ice as a house inhabited by algae, the algae would live in the basement, at the bottom of the sea ice, often covered by a "roof" of snow.

\section{ALGAE NEED TO EAT... AND TO BE EATEN}

Having a house, of course, is not all that algae need to live; they also need food. Algae are plants, so they need sunlight and carbon to perform photosynthesis [2], to create the energy they need to grow. Carbon is usually contained in sea water, so each brine pocket has a bit of carbon that can be used by the algae. What about sunlight? In the Arctic during the summer, days become so long that there is no night for about 2 months. On the other hand, in winter, the nights are so long that there is no light at all. Thus, algae can grow only in summer, when there is sunlight, and they die in winter, when it is dark. Dead algae are broken down and their nutrients are recycled, the same way plants that grown on land are. Algae are important because they are food for animals. As on land, the ocean is populated by small animals that eat plants. These animals are similar to shrimps or insects, but very small. The animals that eat plants are then eaten by bigger animals, like fish. Fish are eaten by birds and seals, which are then eaten by the biggest predator in the Arctic: the polar bear. Thus, sea-ice algae are important in the Polar regions because they are the first link in the Arctic marine food chain.

\section{A LONG WAY FROM THE SUN TO THE EARTH}

The light that we receive every day on the Earth originates from the Sun, our very own star. This light, which is sent permanently by the Sun in the form of rays, has to make a long journey through the solar system to reach the Earth. Once the sun rays reach our planet, they still need to get through the atmosphere before they can provide us with energy and warm us up. The atmosphere is the huge layer of air around the Earth's surface that allows us to breathe. It is composed of a lot of tiny molecules of different gases. When the sun's rays cross the atmosphere, some of them are reflected back into space by the gas molecules and also by the little water droplets that form the clouds (Figure 2). Other rays are absorbed by the particles. So, only a little more than half of the sun's rays $(\sim 55 \%)$ will reach the Earth's surface [3]. 


\section{Figure 2}

Light has a long and difficult journey from the sun to the sea-ice algae. The yellow arrows represent the sunlight. The width of the arrows represents the amount of light: the thinner the arrow, the less sunlight available. Some of the sun's rays are reflected back into the atmosphere by the snow layer, and some of the rays are absorbed by the snow and the ice. The amount of light that reaches the algae is very small compared to the amount of light that originally hit the snow.
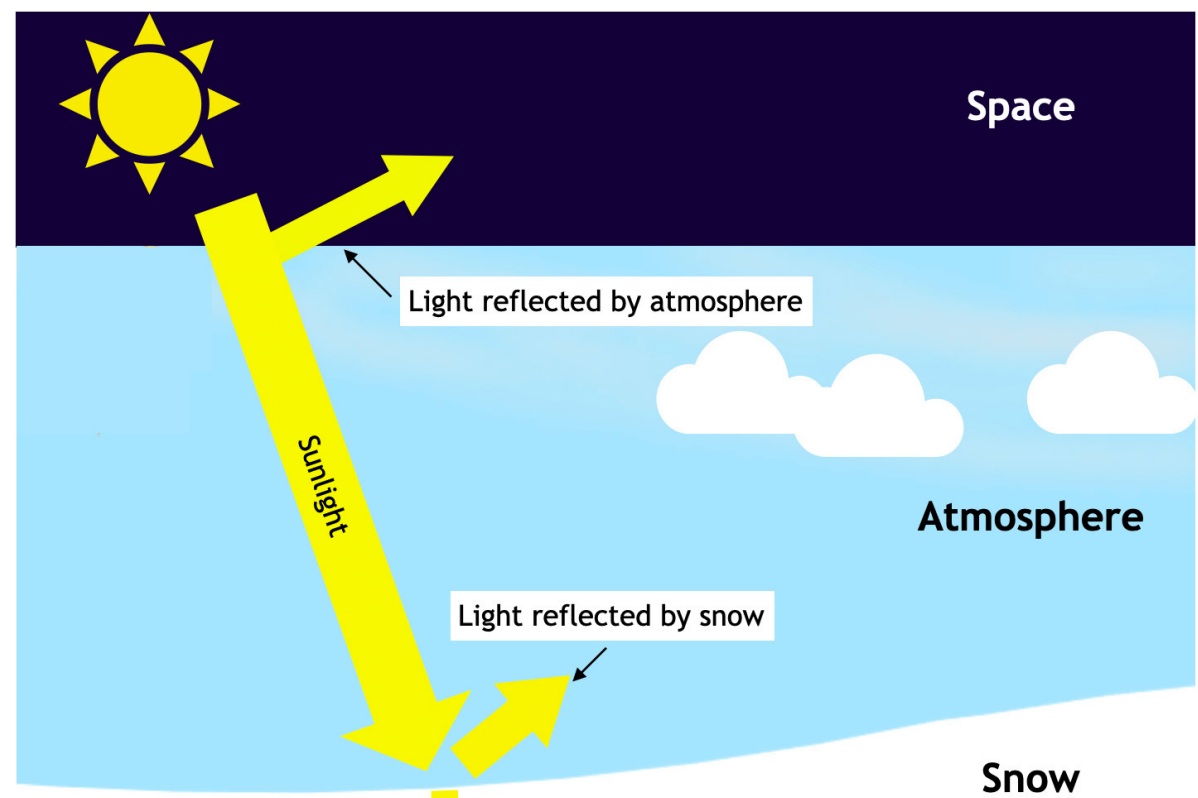

Light able to go through snow and ice

Light reaching algae -

Sea ice

Algae

\section{Light reaching} the ocean

Ocean

Figure 2

\section{THE DIFFICULT JOURNEY OF SUNLIGHT THROUGH THE SEA ICE}

We learned that algae live at the bottom of sea ice, which can be covered by snow. We also learned that, as plants, algae need sunlight to grow. But how is the sunlight capable of making it through the thick ice and snow to finally reach the little algae, to give them energy? The layer of snow is made of a large number of snowflakes packed together. Most of the sunlight that hits the snow is reflected back to the atmosphere, because the snow almost acts like a mirror. This is why it is always hard to look at the bright snow when the sun shines. Just like in the atmosphere, some of the sunlight is absorbed by the snowflakes, warming up the snow and contributing to its melting. It is much more difficult for the sunlight to pass through snow than to pass through the atmosphere though, because the snowflakes are more densely packed than the tiny gas molecules in the atmosphere. However, some rays find their way through. Those sun rays that make it through the snow layer will then encounter the sea ice below. Sea ice is ten times easier for the sun rays to cross than the snow is, since the ice is usually clearer than snow, with fewer particles and no snowflakes. But the sea ice is usually thicker than the snow, which again makes it harder for the 
CLIMATE

CHANGE/CLIMATE

\section{WARMING}

Worldwide increase in temperature and change in climate as response to human activities. sunlight to reach the algae's living place. Eventually, some of the sun's rays reach the bubbles where the algae live, making it possible for the algae to enjoy a bit of sunlight. But that is not the end! Once the sun's rays have filled the algae with energy, some leftover rays continue their journey deeper into the ocean water, giving their energy to other plants and animals until all the light rays are used up (Figure 2).

\section{WHAT ABOUT THE FUTURE OF ALGAE?}

Many activities that we do as humans have led to pollution, resulting in a heating of the atmosphere called climate change or climate warming. Climate warming can already be measured today and will continue for a long time into the future. It is important for us to understand what this warming will mean for the different regions of the planet, including the Arctic. As it turns out, the Arctic is warming faster than the rest of planet, leading to less snow cover and thinner sea ice. As a consequence, it is easier for the sunlight to find its way through the ice to reach the algae. For the algae, this means that, in the future, there will most likely be more light available, and thus more energy to use to grow. But, scientists from all around the world have calculated that, sometime in the future, the sea ice will very likely disappear completely each summer. If the sea ice disappears each summer, there will be no housing for the sea-ice algae to live in. This means that climate change is a big threat to sea-ice algae.

Arctic research tries to understand the consequences of climate change for the Arctic, the atmosphere, the sea ice, the ocean, the plants and animals, and the humans. Our focus is on the sea-ice algae and the place they live, which is the sea-ice cover of the Arctic Ocean. We tell many people about our work and what we have discovered about the changes in the Arctic, so that people, including politicians, can have a better idea of what is happening now and what might happen in future. This knowledge will help us to make the proper decisions for the future of our planet.

\section{REFERENCES}

1. Glessmer, M. 2019. How does ice form in the sea? Front. Young Minds 7:79. doi: 10.3389/frym.2019.00079

2. Ghosh, T., and Mishra, S. 2017. How does photosynthesis take place in our oceans? Front. Young Minds 5:34. doi: 10.3389/frym.2017.00034

3. Fondriest Environmental, Inc. 2014. Solar Radiation and Photosynethically Active Radiation. Fundamentals of Environmental Measurements. Available online at: https://www.fondriest.com/environmental-measurements/parameters/ weather/solar-radiation/

SUBMITTED: 31 October 2019; ACCEPTED: 29 October 2020; PUBLISHED ONLINE: 26 November 2020. 
EDITED BY: Roxana Suehring, Stockholm University, Sweden

CITATION: Castellani G, Veyssiere G, Kauker F, Karcher M, Stroeve J, Wilkinson JP, Flores $\mathrm{H}$ and Nicolaus M (2020) Freezing in the Sun. Front. Young Minds 8:509101. doi: 10.3389/frym.2020.509101

CONFLICT OF INTEREST: FK and MK were employed by company Ocean Atmosphere Systems $\mathrm{GmbH}$.

The remaining authors declare that the research was conducted in the absence of any commercial or financial relationships that could be construed as a potential conflict of interest.

COPYRIGHT (c) 2020 Castellani, Veyssiere, Kauker, Karcher, Stroeve, Wilkinson, Flores and Nicolaus. This is an open-access article distributed under the terms of the Creative Commons Attribution License (CC BY). The use, distribution or reproduction in other forums is permitted, provided the original author(s) and the copyright owner(s) are credited and that the original publication in this journal is cited, in accordance with accepted academic practice. No use, distribution or reproduction is permitted which does not comply with these terms.

\section{YOUNG REVIEWERS}

\section{ECOLE PRIMAIRE PAUL BAUDRIN, AGE: 10}

At the Aslonnes school, there are five classes for children from 3 to 10 years old. In our CM2 class (fifth grade), we are 12 girls and 10 boys. We have everything we need to work and to do sports. The pupils are very intelligent and very wise and the teachers are very nice. We were very interested in the topic of sea ice. Maybe some students will become scientists.

\section{AUTHORS}

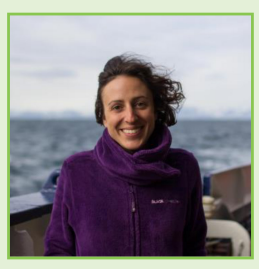

\section{GIULIA CASTELLANI}

Dr. Giulia Castellani is an Italian scientist working in Germany at the Alfred Wegener Institute. Since she was a teenager she has been fascinated by polar regions and ice. Giulia took part in several expeditions to the Arctic and to the Antarctic. She studies the habitat properties of sea ice and their effect on the sea-ice algae. Part of her job is also to work at the computer with virtual environments that can simulate the life of algae in sea ice. * giulia.castellani@awi.de

\section{GAELLE VEYSSIERE}

Dr. Gaëlle Veyssiere is a sea ice scientist working at the British Antarctic Survey in the UK. Gaëlle has always been fascinated by snowy and icy surfaces on Earth and beyond. After studying snow in the French mountains using satellite data during her Ph.D., she decided to study sea ice and snow in the Arctic and the light journey through them. To do that, she has been doing fieldwork, working with collected and satellite data, and also models. 

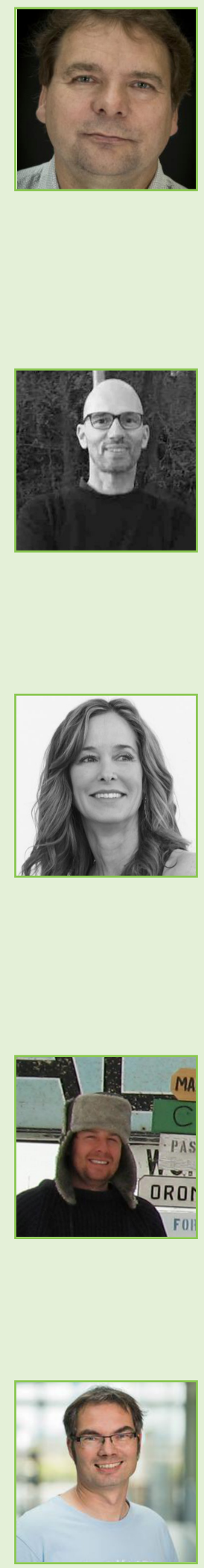

\section{FRANK KAUKER}

Dr. Frank Kauker from education I am a theoretical physicist. In my diploma I "looked" at the smallest particles of matter we know about, at quarks. After the diploma I wanted to work in areas of more social relevance and made my Ph.D. on climate change in the North Sea. In the last years I was mainly concerned with the fusion of earth observations (in-situ and satellite) with computer models for better predictions of sea-ice conditions in Polar regions. This is as well my contribution to the project EcoLight: I help to utilize EcoLight observation in a sea ice-ocean computer model.

\section{MICHAEL KARCHER}

I am a physical oceanographer. My main interest is to understand how the oceans move, how they develop over time, and interact with the sea ice, the atmosphere, and also how this impacts marine plants and animals. My main research region is the Arctic, and to investigate its ocean, ice, and atmosphere system I use computer models and measurements. In the project EcoLight I work with biologists and other polar researchers to understand the impact of a reducing Arctic Sea Ice cover on ice algae.

\section{JULIENNE STROEVE}

Julienne C. Stroeve received a Ph.D. in geography from the University of Colorado Boulder, in 1996, for her work in understanding Greenland climate variability. Subsequently she became a senior research scientist at the National Snow and Ice Data Center (NSIDC) at the University of Colorado, a Professor at University College London and more recently a Canada 150 Chair at the University of Manitoba. Her Arctic research interests are wide-ranging, and include remote sensing, sea ice forecasting, atmosphere-sea ice interactions, climate change, and impacts within and beyond the Arctic.

\section{JEREMY P. WILKINSON}

Dr. Jeremy Wilkinson studies the frozen ocean in the Arctic and Antarctic. He works for British Antarctic Survey, Cambridge, UK. Over the past 25 years he has organized and participated more than 20 polar field expeditions, and during this time he has witnessed the loss of almost half the summer Arctic sea ice. Jeremy has a lot of experience in working with scientists from many countries, and in many different fields of science. He enjoys an excellent working relationship with the international scientific community and other stakeholders in the Polar regions.

\section{HAUKE FLORES}

Hauke Flores studied biology in Hamburg. Afterwards, he worked as a fisheries observer (a person recording the fish caught with commercial fishing vessels). During his Ph.D. thesis at the University of Groningen (2003-2009), Hauke studied animals living at the sea-ice underside in Antarctica. In 2012 he moved from the Netherlands back to Germany. Here, he headed the Young Investigators Group Iceflux at AWI. Since 2017, Hauke has a permanent position as a scientist at AWI. Hauke has participated in 12 expeditions to the Antarctic and Arctic Oceans. 


\section{MARCEL NICOLAUS}

Marcel Nicolaus has a strong expertise in physical properties of snow and sea ice in the Arctic and Antarctic from field observations, numerical simulations, airborne measurements, autonomous platforms, and remote-sensing data. He has joined more than 20 field campaigns to Arctic and Antarctic sea ice in different seasons. Currently, he is employed as a senior scientist at the AWI, and he is/was PI in different national and international projects studying linkages of sea ice with the atmosphere and ocean. 